\title{
PENDAMPINGAN PENGELOLAAN KEUANGAN DESA ADAT CEPAKA
}

\author{
Tiara Kusuma Dewi'1), Kukuh Rian Setiawan¹) \\ 1) Program Studi Akuntansi, Fakultas Bisnis Sosial dan Humaniora, Universitas Triatma Mulya, Badung, Bali, Indonesia \\ Corresponding author: Tiara Kusuma Dewi \\ E-mail : kusuma.dewi@triatmamulya.ac.id
}

Diterima 30 November 2021, Direvisi 07 Desember 2021, Disetujui 07 Desember 2021

\begin{abstract}
ABSTRAK
Pengelolaan keuangan pada suatu lembaga diperlukan keahlian maupun keterampilan yang dimiliki oleh pengelolanya sehingga dapat menghasilkan suatu laporan keuangan yang transaparan, akuntabel dan memiliki kredibilitas yang baik, pengelolaan keuangan dapat dilaksanakan dengan cara manual maupun menggunakan perangkat bantuan guna efisiensi pada jumlah laporan dan waktu dalam proses pengerjaanya, Badan Usaha Milik Desa atau biasa disebut dengan BUMDES desa Cepaka telah memiliki beberapa unit usaha dimana dalam pelaporannya masih menggunakan model pelaporan manual dan sederhana, kegiatan pengabdian masyarakat ini bertujuan untuk memberikan pendampingan dalam pengelolaan keuangan sehingga laporan keuangan yang dibuat dapat diminamilisir kesalahannya, hasil yang dicapai pada program pengabdian masyarakat ini adalah Pihak BUMDES menyetujui bahwa diperlukannya analisa terkait pemberian kredit, dan juga menambah lagi dilakukannya analisa rekam jejak nasabah melalui informasi dari koperasi-koperasi di Desa Cepaka. Sedangkan dalam hal pengawasan. untuk saat ini masih bisa dilakukan pengawasan hanya berdasarkan data laporan rekening koran Tabungan setiap bulannya dan karena cash flow yang masih kecil ,menyebabkan jarang terjadinya transaksi pada Bank.
\end{abstract}

Kata kunci: pelaporan keuangan; pengelolaan keuangan; pendampingan.

\begin{abstract}
Financial management at an institution requires expertise and skills possessed by the manager so that it can produce a financial report that is transparent, accountable and has good credibility, financial management can be carried out manually or using assistance tools for efficiency in the number of reports and time in the process. , Village-Owned Enterprises or commonly referred to as BUMDES Desa Cepaka already has several business units where the reporting still uses a manual and simple reporting model, this community service activity aims to provide assistance in financial management so that the financial reports that are made can be minimized for errors, the results obtained are The achievement in this community service program is that the BUMDES party agrees that an analysis is needed regarding lending, and also adds to the analysis of customer track records through information from cooperatives in Cepaka Village. While in terms of supervision. For now, monitoring can still be carried out based on data from the Savings Account statement every month and because the cash flow is still small, it causes transactions to rarely occur at the Bank.
\end{abstract}

Keywords: financial reporting; financial management; mentoring.

\section{PENDAHULUAN}

Menurut Peraturan Pemerintah

Republik Indonesia, 1999 yang dimaksud dengan Badan Usaha Milik Desa (BUMDesa) adalah Lembaga usaha desa yang dikelola oleh masyarakat dan pemerintah desa dalam upaya memperkuat perekonomian desa dan dibentuk berdasarkan kebutuhan dan potensi desa. sedangkan menurut (Kusnadi, 2015) bahwa desa dapat mendirikan badan usaha milik desa sesuai dengan kebutuhan dan potensi desa. hal tersebut diperkuat dengan UU nomor 6 tahun 2014 tentang desa diijinkan untuk mendirikan BUMDesa,
Peraturan menteri desa nomor 6 tahun 2020 tentang pedoman pendirian, pengurusan, pengelolaan dan pembubaran BUMDesa. Pembentukan suatu BUMDesa menurut (PP no 72 tahun 2005 pasal 1 sekurangkurangnya memuat mengenai bentuk badan hukum, kepengurusan, hak dan kewajiban, permodalah, bagi hasil usaha atau keuntungan, kerjasama dengan pihak ketiga, mekanisme pengelolaan dan pertanggungjawaban

BUMDes merupakan salah satu usaha yang dimiliki oleh suatu Desa dalam memasarkan produk baik produk yang merupakan hasil dari desa tersebut maupun 
produk lain yang memiliki nilai jual. (Sofyani dkk, 2019). Pendirian dan pengelolaan BUMDesa adalah perwujudan dari pengelolaan ekonomi produktif desa yang dilakukan secara kooperatif, partisipatif, emansipatif, transparansi, mempunyai akuntabilitas dan sustainability. Perwujudan dari transparansi, akuntabilitas dan sustainabilitas dapat dituangkan salah satunya dalam bentuk laporan keuangan (Melatyugra, dkk, 2021). (Babulu, 2020), menjelaskan bahwa membuat laporan keuangan merupakan tahap akhir dari siklus akuntansi. Data laporan keuangan diambil dari seluruh proses yang dilakukan sampai dibuatnya laporan posisi keuangan. Akuntabilitas keuangan adalah pertanggungjawaban bukan hanya kepada pihak yang berwajib dalam hal ini adalah tingkat pemerintahan yang lebih tinggi namun juga kepada masyarakat, (Idawati dan Eleonora, 2020). Pertanggungjawaban keuangan yang dikelola oleh BUMDesa adalah kepada pemerintah desa dan kepada masyarakat desa.

BUMDes merupakan salah satu usaha yang dimiliki oleh suatu Desa dalam memasarkan produk baik produk yang merupakan hasil dari desa tersebut maupun produk lain yang memiliki nilai jual. (Titioka, dkk, 2020). BUMDes Desa Adat Cepaka merupakan usaha milik Desa yang sedang berkembang dan sedang dalam fase pemulihan setelah mengalami keterpurukan dari sisi finansial dan manajemen. Perlu dukungan dari seluruh komponen masyarakat agar pembangunan di Desa Adat Cepaka bisa terlaksana dengan baik.BUMDes Desa Adat Cepaka merupakan salah satu Desa yang sedang berkembang dan masih dalamdan usaha milik desa yang sedang dalam fase pemulihan setelah mengalami keterpurukan dari sisi finansial dan manajemen. Perlu dukungan dari seluruh komponen masyarakat agar pembangunan di Desa Adat Cepaka bisa terlaksana dengan baik.

$\begin{array}{ccc}\text { Misi } & \text { Desa } & \text { Cepaka dibidang } \\ \text { pembangunan salah satunya yaitu }\end{array}$ meningkatkan ketahanan ekonomi dengan menggalakkan usaha ekonomi kerakyatan , melalui program strategis di bidang produksi pertanian, pemasaran ,Usaha kecil dan menengah (UMKM) serta Koperasi dan LPD (Lembaga Perkreditan Desa).

Pandemi Covid 19, membuat aktivitas desa ini menjadi tertutup dan berdampak pada semua sektor di Desa Cepaka. Pada BUMDes Adat Cepaka sangat dirasakan untuk transaski yang terjadi selama pandemi covid-19 sangat menurun. Usaha yang bertumpu pada kegiatan dan usaha masyarakat adat perlu strategi dalam pemasaran dan pengelolaan keuangan yang baik sehingga mampu memberikan benefit yang berimbang. Selain masalah penurunan transaksi terdapat permasalahan lain dalam proses pembukuan yaitu Proses pencatatan transaksi secara konvensional dapat menimbulkan risiko, Penutupan sector pariwisata bagi wisatawan asing berdampak pada pekerja pariwisata yang tidak mampu membiayai kehidupan keluarga sehingga kehidupan ekonomi dan social mereka juga terganggu.

Desa Cepaka sebagai desa mitra Universitas Triatma Mulya memiliki banyak potensi wisata dan usaha yan dapat dikembangkan, namun keterbatasan ilmu pengetahuan mereka tentang pembukuan menjadi kendala dalam keuangan desa wisata tersebut. Kompetensi yang dibutuhkan oleh Desa Cepaka dimiliki oleh dosen dan mahasiswa secara utuh, sehingga implementasi program PKM ini berpotensi dapat dilaksanakan secara optimal.

Berdasarkan permasalahan yang terjadi, maka tujuan program PKM adalah memberikan pendampingan dalam pengelolaan keuangan di BUMDes Cepaka sehingga proses pencatatan pembukuan sudah tidak secara konvensional lagi.

\section{METODE}

Kegiatan Pengabdian Kepada Masyarakat ini dilaksanakan di Desa Adat Cepaka, Kecamatan Kediri, Kabupaten Tabanan Provinsi Bali dimulai pada bulan Juli 2021 hingga bulan November 2021, Mitra PKM merupakan para pegawai BUMDes adat Cepaka dengan jumlah peserta sebanyak 14 orang.

Metode Pelaksanaan PKM dimulai dari workshop dan sosialiasi pentingnya pengetahuan tentang prosedur transaksi keuangan serta pencatatannya dan dilanjutkan dengan pendampingan serta pembekalan guna menambah pengetahuan para peserta yang menjadi mitra PKM.

Program kerja yang dilaksanakan dalam pengabdian masyarakat ini kami mengacu pada hasil observasi yang telah dilaksanakan sehingga program yang akan dilaksanakan nantinya dapat disesuaikan dengan kebutuhan (sesuai situasi dan kondisi). Rincian program kerja PKM Universitas Triatma Mulya terdiri dari:

a. Pendampingan serta Pembekalan dalam Prosedur Transaksi pada Tabungan.

b. Pendampingan dan Pembekalan Prosedur Permohonan Kredit \& Transaksi Kredit.

c. Pendampingan dan Pembekalan Prosedur Operasional pada Teller/Kasir. 


\section{d. Pendampingan dan Pembekalan} Pembuatan Laporan Keuangan di BUMDes.

\section{HASIL DAN PEMBAHASAN}

Berdasarkan tujuan dari pelaksanaan kegiatan PKM, terdapat beberapa program yang dapat direalisasikan pada BUMDes Adat Cepaka dijelaskan pada tabel 1 berikut:

Tabel 1 Hasil Pelaksanaan Program Kerja BUMDES Desa Adat Cepaka

\begin{tabular}{|c|c|c|c|}
\hline $\begin{array}{c}\text { Program } \\
\text { Kerja }\end{array}$ & $\begin{array}{c}\text { Kegiata } \\
\mathbf{n}\end{array}$ & $\begin{array}{l}\text { Tindak } \\
\text { Lanjut }\end{array}$ & Hasil \\
\hline $\begin{array}{l}\text { Pendampin } \\
\text { gan dan } \\
\text { pembekala } \\
\text { n prosedur } \\
\text { transaksi } \\
\text { tabungan }\end{array}$ & $\begin{array}{l}\text { Diskusi } \\
\text { dan } \\
\text { memberik } \\
\text { an } \\
\text { masukan } \\
\text { mengenai } \\
\text { penganalis } \\
\text { aan kredit }\end{array}$ & $\begin{array}{l}\text { Menyarankan } \\
\text { agar } \\
\text { menggunaka } \\
n \text { indikator- } \\
\text { indikator } \\
\text { (syarat) } \\
\text { tertentu } \\
\text { dalam } \\
\text { pemberian } \\
\text { kredit. } \\
\text { Contohnya } \\
\text { nasabah } \\
\text { wajib memiliki } \\
\text { kemampuan } \\
\text { dalam pam } \\
\text { pengembalia } \\
n \quad \text { kredit } \\
\text { (memiliki } \\
\text { usaha/pekerj } \\
\text { aan) }\end{array}$ & $\begin{array}{l}\text { Pihak } \\
\text { BUMDES } \\
\text { menyetujui } \\
\text { bahwa } \\
\text { diperlukannya } \\
\text { analisa terkait } \\
\text { pemberian } \\
\text { kredit, dan } \\
\text { juga ditambah } \\
\text { lagi } \\
\text { dilakukannya } \\
\text { analisa rekam } \\
\text { jejak nasabah } \\
\text { melalui } \\
\text { informasi dari } \\
\text { koperasi- } \\
\text { koperasi di } \\
\text { Desa Cepaka } \\
\text { apakah } \\
\text { nasabah } \\
\text { tersebut } \\
\text { memiliki } \\
\text { masalah kredit } \\
\text { macet di } \\
\text { koperasi } \\
\text { tersebut atau } \\
\text { tidak. }\end{array}$ \\
\hline $\begin{array}{l}\text { Pendampin } \\
\text { gan dan } \\
\text { pembekala } \\
\text { n prosedur } \\
\text { permohona } \\
\text { n kredit } \\
\text { dan } \\
\text { transaksi } \\
\text { kredit }\end{array}$ & $\begin{array}{l}\text { Diskusi } \\
\text { dan } \\
\text { memberik } \\
\text { an } \\
\text { masukan } \\
\text { mengenai } \\
\text { prosedur } \\
\text { operasion } \\
\text { al } \\
\text { Teller/Kasi } \\
\text { r, meliputi } \\
\text { Pembuata } \\
\text { n Laporan } \\
\text { Penyeraha } \\
\text { n Kas Awal } \\
\text { Teller. }\end{array}$ & $\begin{array}{l}\text { Menyarankan } \\
\text { agar } \\
\text { menggunaka } \\
n \text { form bukti } \\
\text { kas keluar } \\
\text { sebagai bukti } \\
\text { penyerahan } \\
\text { kas awal dari } \\
\text { Kepala } \\
\text { BUMDES } \\
\text { kepada } \\
\text { Teller. } \\
\text { Contohnya } \\
\text { pada saat } \\
\text { dimulainya } \\
\text { kegiatan } \\
\text { operasional } \\
\text { BUMDES, } \\
\text { Kepala } \\
\text { BUMDES } \\
\text { akan }\end{array}$ & $\begin{array}{l}\text { Pihak } \\
\text { BUMDES } \\
\text { sangat } \\
\text { menerima } \\
\text { masukan } \\
\text { tersebut, } \\
\text { karena } \\
\text { menurut } \\
\text { Kepala } \\
\text { BUMDES } \\
\text { untuk saat ini } \\
\text { BUMDES } \\
\text { Desa } \\
\text { Pakraman } \\
\text { Cepaka } \\
\text { memerlukan } \\
\text { sistem } \\
\text { tersebut dalam } \\
\text { kegiatan } \\
\text { operasionalny } \\
\text { a. }\end{array}$ \\
\hline
\end{tabular}

\begin{tabular}{|c|c|c|c|}
\hline & & $\begin{array}{l}\text { menyerahkan } \\
\text { sejumlah kas } \\
\text { kepada } \\
\text { Teller. Pada } \\
\text { saat itu, } \\
\text { Kepala } \\
\text { BUMDES } \\
\text { membuat } \\
\text { form bukti kas } \\
\text { keluar. }\end{array}$ & \\
\hline $\begin{array}{l}\text { Pendampin } \\
\text { gan dan } \\
\text { pembekala } \\
n \text { prosedur } \\
\text { operasiona } \\
\text { I teller atau } \\
\text { kasir }\end{array}$ & $\begin{array}{l}\text { Diskusi } \\
\text { dan } \\
\text { memberik } \\
\text { an } \\
\text { masukan } \\
\text { mengenai } \\
\text { prosedur } \\
\text { setoran } \\
\text { tabungan } \\
\text { (BKM) }\end{array}$ & $\begin{array}{l}\text { Memastikan } \\
\text { agar jumlah } \\
\text { setoran } \\
\text { tabungan } \\
\text { nasabah } \\
\text { yang diterima } \\
\text { kolektor } \\
\text { harus sama } \\
\text { antara buku } \\
\text { tabungan } \\
\text { dengan } \\
\text { Laporan } \\
\text { transaksi } \\
\text { harian } \\
\text { kolektor }\end{array}$ & $\begin{array}{l}\text { Pihak } \\
\text { BUMDES } \\
\text { sudah } \\
\text { melakukan } \\
\text { prosedur } \\
\text { tersebut }\end{array}$ \\
\hline $\begin{array}{l}\text { Pendampin } \\
\text { gan dan } \\
\text { pembekala } \\
\mathrm{n} \\
\text { pembuatan } \\
\text { laporan } \\
\text { keuangan } \\
\text { BUMDES }\end{array}$ & $\begin{array}{l}\text { Diskusi } \\
\text { dan } \\
\text { memberik } \\
\text { an } \\
\text { masukan } \\
\text { mengenai } \\
\text { pencatata } \\
n \quad \text { Buku } \\
\text { Bank }\end{array}$ & $\begin{array}{l}\text { Menyarankan } \\
\text { petugas/Pate } \\
\text { ngan } \\
\text { mencatat } \\
\text { setiap } \\
\text { transaksi } \\
\text { yang } \\
\text { berhubungan } \\
\text { dengan Bank } \\
\text { seperti } \\
\text { Penyetoran , } \\
\text { Penarikan, } \\
\text { Adm Bank, } \\
\text { Pendapatan } \\
\text { Bunga Bank, } \\
\text { Biaya Pajak } \\
\text { Bunga Bank }\end{array}$ & $\begin{array}{l}\text { Pihak } \\
\text { BUMDES } \\
\text { menerima } \\
\text { saran tersebut } \\
\text { dan akan } \\
\text { melakukan } \\
\text { pada tahap } \\
\text { selanjutnya. } \\
\text { Untuk saat ini } \\
\text { masih bisa } \\
\text { dilakukan } \\
\text { pengawasan } \\
\text { hanya } \\
\text { berdasarkan } \\
\text { data laporan } \\
\text { rekening koran } \\
\text { Tabungan } \\
\text { setiap dan } \\
\text { bulannya dan } \\
\text { karena cash } \\
\text { flow yang } \\
\text { masih } \\
\text { kecil ,menyeba } \\
\text { bkan jarang } \\
\text { terjadinya } \\
\text { transaksi pada } \\
\text { Bank. }\end{array}$ \\
\hline
\end{tabular}

Kegiatan PKM yang dilakukan diharapkan dapat memberikan dampak positif guna membantu pengelolaan keuangan BUMDes Adat Cepaka dengan tujuan melakukan pendampingan secara langsung dimulai dari mengobservasi terlebih dahulu pokok permasalahan, menentukan program kerja dan 
merealisasikannya bersama stakeholder sehingga kegiatan yang telah disusun dapat berjalan dengan lancar, pendampingan pengelolaan keuangan diharapkan dapat memberikan dampak positif bagi warga Desa Adat Cepaka sehingga kedepannya dapat mengelola keuangannya secara mandiri dengan lebih baik, efisien dan akuntabel.

Beberapa dokumentasi yang dapat dikumpulkan dimulai dari kordinasi penyusunan program kerja sebagai tahap awal dapat dilihat pada gambar 1 .

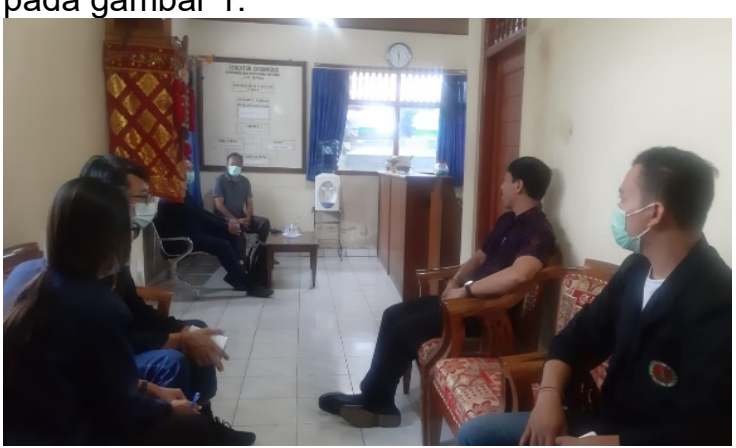

Gambar 1. Kordinasi Penyusunan Program Kerja

Setelah penyusunan program kerja tersusun, selanjutnya pengaplikasian pendampingan yang dilakukan kepada mitra, dimulai dengan pendampingan penyusunan laporan keuangan yang ditunjukkan pada gambar 2.

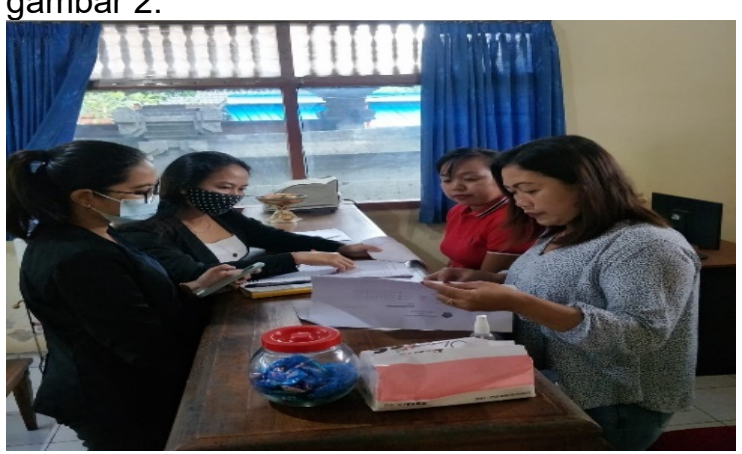

Gambar 2. Pendampingan Penyusunan Laporan Keuangan

Selanjutnya pendampingan juga dilakukan untuk memahami prosedur permohonan kredit sehingga dapat menambah wawasan para mitra PKM untuk memahami dan mematuhi SOP yang telah ditentukan sebelumnya, pendampingan prosedur permohonan kredit ditunjukkan pada gambar 3 .

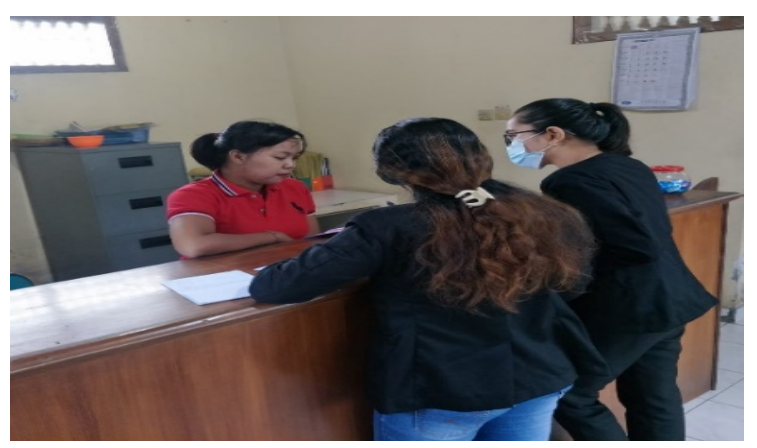

Gambar 3. Pendampingan Prosedur Permohonan Kredit

Selanjutnya pada program PKM ini juga menyelipkan pendampingan prosedur operasional kasir sehingga para pegawai BUMDes adat Cepaka dapat lebih memahami bagaimana prosedur operasional kasir sesuai SOP yang ditunjukkan pada gambar 4 .

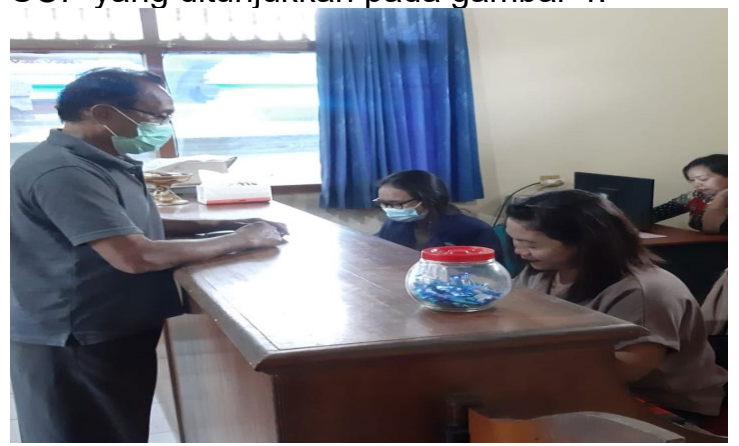

Gambar 4. Pendampingan Prosedur Operasional Kasir

\section{SIMPULAN DAN SARAN}

Berdasarkan hasil pelaksanaan PKM di BUMDes Adat Cepaka dapat disimpulkan bahwa telah terbentuk pemahaman dari para pengurus BUMDes Adat Cepaka tentang proses pembukuan dan pengelolaan keuangan secara benar seperti laporan harian, bulanan dan laporan laba rugi serta diberikan pemahaman kepada Pengurus BUMDes Adat Cepaka pentingnya pembagian tugas dan tanggung jawab antara bagian administrasi dan bagian lapangan, dan berdasarkan hasil PKM diketahui bahwa telah terbentuk mindset positif SDM selaku pengelola menerapkan strategi pemasaran dan berinovasi dengan produkproduk unggulan yang sesuai dengan kebutuhan nasabahnya.

\section{UCAPAN TERIMAKASIH}

Kegiatan PKM ini dapat terlaksana tanpa bantuan dan dukungan dari berbagai pihak, dalam kesempatan ini kami mengucapkan terimakasih yang sebesarbesarnya kepada LPPPM Universitas Triatma Mulya, Dekan Fakultas Bisnis dan Sosial Humaniora Universitas Triatma Mulya, Kepala Desa Cepaka, serta seluruh pihak yang telah 
terlibat dalam PKM ini.

\section{DAFTAR RUJUKAN}

Babulu, N. L. (2020). Faktor-Faktor Yang Mempengaruhi Akuntabilitas Dalam Pengelolaan Dana Desa Dan Dampaknya Terhadap Pencegahan Fraud. Ekopem: Jurnal Ekonomi Pembangunan, 5(2), 1826.

Idawati, W., \& Eleonora, L. (2020). Penerapan Sistem Pengendalian Intern Dan Akuntabilitas Keuangan Dalam Mewujudkan Kualitas Laporan Keuangan. Equity, 22(2), 153. Https://Doi.Org/10.34209/Equ.V22i2.1367

Kemendesa. (2020). Peraturan Menteri Desa Nomor 6 Tahun 2020. Menteri Desa, Pembangunan Daerah Tertinggal, Dam Transmigrasi Republik Indonesia, 53(9), 1689-1699.

Kusnadi, A. (2015). Perkembangan Politik Hukum Pemerintahan Desa Menurut Undang-Undang Nomor 32 Tahun 2004 Tentang Pemerintahan Daerah Dan Undang-Undang Nomor 6 Tahun 2014 Tentang Desa. Padjadjaran Jurnal IImu Hukum (Journal Of Law), 2(3), 564-580. Https://Doi.Org/10.22304/Pjih.V2n3.A8

Melatyugra, N., Wauran, I., Prananingrum, D. H., Rauta, U., \& Rissy, Y. Y. W. (2021). Pengelolaan Bumdes: Aspek Hukum Dan Regulasi. Magistrorum Et Scholarium: Jurnal Pengabdian Masyarakat, 1(2), 215-224.

Https://Doi.Org/10.24246/Jms.V1i22020p 215-224

Peraturan Pemerintah Republik Indonesia. (1999). Peraturan Pemerintah Republik Indonesia Nomor 72 Tahun 2005. Peraturan Pemerintah Republik Indonesia Nomor 26 Tahun 1985 Tentang Jalan, 2003(1), 1-5.

Sofyani, H., Atmaja, R., \& Rezki, S. B. (2019). Success Factors Of Village-Owned Enterprises (Bumdes) Performance In Indonesia: An Exploratory Study. Journal Of Accounting And Investment, 20(2). Https://Doi.Org/10.18196/Jai.2002116

Titioka, B., Huliselan, M., Sanduan, A., Ralahallo, F., \& Siahainenia, A. (2020). Pengelolaan Keuangan Bumdes Di Kabupaten Kepulauan Aru. Jurnal Pengabdian Masyarakat Jamak, 3(1), 197-216. 